\title{
ESTUDIO COMPARATIVO DE FRECUENCIAS DE TOXOPLASMOSIS EN PORCINOS PROCEDENTES DE CRIANZA TECNIFICADA Y NO TECNIFICADA*
}

\author{
José Bustamante V. ${ }^{1}$ y Francisco Suárez A. ${ }^{2}$
}

\section{Nistrat}

The incidence of toxoplasmosis in swineherds from Lima, Peru, was evaluated by serological tests utilizing qualitative and quantitative indirect hemagglutination methods. A total of 310 pigs were sampled, including 155 (males $n=77$ and females $n=78$ ) from highly controlled commercial production situations and 155 (males $n=73$ and females $\mathrm{n}=82$ ) reared in poor sanitary conditions. Among the animals reared in good sanitary conditions the frequency of toxoplasmosis reactors was $25.16 \%(18.33-31.99 \%$ at $95 \%$ confidence), while the animals reared in poor conditions registered $14.84 \%(9.24-20.44 \%$ at $95 \%$ confidence). There was also a significant difference $(\mathrm{P}<0.05)$ in the frequency of females reactors among the different commercial herds tested, while the poorly maintained herds showed no deviation ( $\mathrm{P}>0.05$ ). Antibody levels were low in virtually all the pigs tested. This study documents the presence of swine toxoplasmosis in Lima pig farms with the consequent danger to humans of a contaminated meat supply.

Key Words: Toxoplasmosis, swine.

\section{Revuruen}

Con la finalidad de evaluar la situación de la toxoplasmosis porcina en la ciudad de Lima y comparar las frecuencias de esta zoonosis en animales procedentes de dos tipos de crianza, se obtuvieron muestras de sueros de 310 cerdos, de los cuales 155 (machos $n=77$ y hembras $n=78$ ) fueron de crianza tecnificada y 155 (machos $n=73$ y hembras $n=82$ ) de crianza no tecnificada durante su beneficio en dos mataderos de esta ciudad. La evaluación se efectuó a través de kits comerciales de la prueba de hemaglutinación indirecta, en forma cualitativa y cuantitativa. Los resultados, determinaron una frecuencia de reactores a toxoplasmosis de $25.16 \%$ con intervalo de confianza de $95 \%$ entre $18.33 \%$ y $31.99 \%$ en animales de una granja de crianza tecnificada y $14.84 \%$ con intervalo de confianza de $95 \%$ entre $9.24 \%$ y $20.44 \%$ en animales de crianza no tecnificada. Las evaluaciones de reactores a toxoplasmosis según el sexo, mostraron diferencia significativa $(P<0.05)$ en hembras procedentes de crianza tecnificada, mientras que en los otros animales no se observó diferencia estadística $(P>0.05)$. En la mayoría de los cerdos evaluados los niveles de anticuerpos fueron bajos. El presente estudio permitió confirmar la importancia en Salud Pública de la toxoplasmosis porcina, constituyendo la carne de esta especie animal una importante fuente de infección para la especie humana, que se refleja en el riesgo de

1 Práctica privada

2 Laboratorio de Medicina Preventiva IVITA - FMV - UNMSM. E.mail: dI70078@unmsm.edu.pe. 
infección a que está sujeto el hombre cuando consume carne de cerdos insuficientemente cocida.

Palabras clave: Toxoplasmosis, porcicultura tecnificada no tecnificada.

\section{merwinetin}

La toxoplasmosis, es una de las enfermedades parasitarias y zoonóticas de mayor difusión en la naturaleza. Se encuentra en todas las latitudes afectando a humanos y a diversas especies de mamíferos domésticos, silvestres y aves en el ámbito mundial, y a pesar que en la mayoría de los casos se manifiesta en forma asintomática o latente en el hombre, en algunas ocasiones produce cuadros patológicos de importancia.

La relevancia de su estudio, está dada por los daños que produce en el ser humano, estimándose que alrededor de un tercio o más de la población mundial posee anticuerpos contra el parásito.

En el humano y en los animales, la toxoplasmosis habitualmente es asintomática y las formas clínicas son variables dependiendo del órgano o sistema donde se multiplica el parásito, aunque sólo en la primoinfección de mujeres embarazadas el parásito cruza la placenta, infectando al feto con consecuencias serias. En pacientes con inmunosupresión, la toxoplasmosis es una infección mucho más severa, resultando en mortalidad y morbilidad significativa, siendo considerada entre las enfermedades oportunistas que con mayor frecuencia, presentândose en los casos de SIDA, enfermedad de Hodgkin y leucemia.

La distribución de la toxoplasmosis en el Perú reviste interés en salud pública, por ser una enfermedad transmisible por alimentos, adquiriendo los animales domésticos un papel importante en la transmisión de la enfermedad al hombre. La carne de cerdo cruda o insuficientemente cocida es considerada una causa importante de infecciones humanas por Toxoplasma gondii. Este es un factor a tener en cuenta, debido al crecimiento de la producción porcina en nuestro país, que en el año de 1998 llegó a tener una población de 2531 474 animales con una producción percapita de $3.3 \mathrm{~kg} /$ habitante.

El presente trabajo se realizó con la finalidad de dar un mayor conocimiento del grado de riesgo de infección al que está expuesta la población humana, al consumir carne de cerdo cruda o insuficientemente cocida. Para esto, se consideró realizar un estudio comparativo de las frecuencias de toxoplasmosis porcina, en animales procedentes de 2 tipos de crianza, una tecnificada y otra no tecnificada.

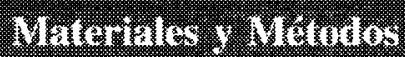

En granjas de crianza tecnificada se muestrearon 155 cerdos de engorde ( 77 machos y 78 hembras), con un peso promedio de $85 \mathrm{~kg}$, sacrificados en el matadero "A" de Lima Metropolitana, procedentes de una granja porcina ubicada en el valle de Lima (Chilca).

En granja de crianza no tecnificada se obtuvieron muestras de sangre de 155 cerdos de engorde ( 73 machos y 82 hembras) con un peso promedio de $70 \mathrm{~kg}$, beneficiados en el matadero " $B$ ", procedentes de los parques porcinos de Lima Metropolitana. 
Las muestras de sangre de cerdos de ambos tipos de crianza, fueron obtenidas en diferentes oportunidades en los mataderos indicados. En el momento de la recolección se identificaron las muestras mediante numeración, teniendo en consideración el sexo del animal. Luego de obtenidas las muestras, fueron llevadas al Laboratorio de Microbiología y Parasitología de la Facultad de Medicina Veterinaria de la Universidad Nacional Mayor de San Marcos, donde se procedió a la separación del suero por medio de centrifugación, almacenándose en viales a $-20^{\circ} \mathrm{C}$ hasta la realización de los análisis serológicos.

Para la determinación cuantitativa y cualitativa de los anticuerpos contra Toxoplasma gondii, se utilizó la prueba de Hemaglutinación Indirecta, en kits comerciales (Salck, Brasil), según el manual proporcionado por la compañia comercial.

Los resultados son expresados en porcentaje, teniendo en consideración la positividad de los sueros a la prueba serológica, calculándose los intervalos de confianza respectivos para los dos grupos según procedencia y realizando la prueba de diferencia de proporciones de infectados según procedencia. Del mismo modo, se realizó la prueba de Chi cuadrado para probar la asociación entre tipo de crianza y sexo.

\section{Resulutus i Disueth}

Los resultados de las evaluaciones serológicas para toxoplasmosis porcina, usando la prueba de Hemaglutinación indirecta son presentados en los Cuadros 1 , 2,3 y 4 .

Tales resultados muestran que la frecuencia de reactores entre los animales procedentes de una granja de crianza tecnificada fue de $25.16 \%$ con un intervalo de confianza del $95 \%$ entre $18.33 \%$ y $31.99 \%$; mientras que entre los cerdos procedentes de crianza no tecnificada fue de $14.84 \%$ con un intervalo de confianza entre $9.24 \% \mathrm{y}$ $20.44 \%$.

Con la finalidad de observar si la diferencia encontrada era debida al azar se aplicó la prueba de diferencia de las proporciones, observándose significancia estadística, que fue corroborada por la prueba de Chi cuadrado $(\mathrm{p}<0.05)$. Esta diferencia puede deberse a la población de gatos observada en las instalaciones de la crianza tecnificada, lo que puede aumentar la disponibilidad de ooquistes de toxoplasma en dichos lugares.

Cuadro 1. Resultados de la evaluación serológica cualitativa por Hemaglutinación Indirecta de cerdos según tipo de crianza.

\begin{tabular}{lcccc}
\hline Diagnóstico & \multicolumn{2}{c}{ Crianza tecnificada } & \multicolumn{2}{c}{ Crianza no tecnificada } \\
\cline { 2 - 5 } & Animales, $\mathrm{n}$ & $\%$ & Animales, $\mathrm{n}$ & $\%$ \\
\hline Positivo & 39 & 25.2 & 23 & 14.8 \\
Negativo & 116 & 74.8 & 132 & 85.2 \\
\hline Total & 155 & 100.0 & 155 & 100.0 \\
\hline $\mathrm{X}^{2}=5.16(\mathrm{p}<0.05)$ & IC $[18.33 \leq \pi \leq 31.99]=0.095$ & IC $[9.24 \leq \pi \leq 20.44]=0.95$
\end{tabular}


Cuadro 2. Resultados de la evaluación serológica cuantitativa por Hemaglutinación Indirecta de cerdos que resultaron positivos a la prueba cualitativa, según tipo de crianza.

\begin{tabular}{ccccc}
\hline \multirow{2}{*}{ Dilución } & \multicolumn{2}{c}{ Crianza tecnificada } & \multicolumn{2}{c}{ Crianza no tecnificada } \\
\cline { 2 - 5 } & Animales, $\mathrm{n}$ & $\%$ & Animales, $\mathrm{n}$ & $\%$ \\
\hline $1: 16$ & 12 & 30.8 & 4 & 17.4 \\
$1: 32$ & 18 & 46.2 & 7 & 30.4 \\
$1: 64$ & 4 & 10.2 & 10 & 43.5 \\
$1: 128$ & 4 & 10.2 & 2 & 8.7 \\
$1: 256$ & 1 & 2.6 & 0 & 0.0 \\
\hline Total & 39 & 100.0 & 23 & 100.0 \\
\hline
\end{tabular}

Cuadro 3. Resultados de la evaluación serológica cualitativa (\%) por Hemaglutinación Indirecta de cerdos según tipo de crianza y sexo.

\begin{tabular}{lcccc}
\hline Diagnóstico & \multicolumn{2}{c}{ Crianza tecnificada } & \multicolumn{2}{c}{ Crianza no tecnificada } \\
\cline { 2 - 5 } & $\begin{array}{c}\text { Machos } \\
(\mathrm{n}=77)\end{array}$ & $\begin{array}{c}\text { Hembras } \\
(\mathrm{n}=78)\end{array}$ & $\begin{array}{c}\text { Machos } \\
(\mathrm{n}=73)\end{array}$ & $\begin{array}{c}\text { Hembras } \\
(\mathrm{n}=82)\end{array}$ \\
\hline Positivo & 15.6 & 34.6 & 11.0 & 18.3 \\
Negativo & 84.4 & 65.4 & 89.0 & 81.7 \\
\hline Total & 100.0 & 100.0 & 100.0 & 100.0 \\
\hline Crianza tecnificada: & $\mathrm{X}^{2}=7.44(\mathrm{p}<0.05)$ & $\begin{array}{l}\text { Machos }: \text { IC }[7.48 \leq \pi \leq 23.68]=0.95 \\
\text { Crianza no tecnificada: } \mathrm{X}^{2}=1.64(\mathrm{p}>0.05)\end{array}$ & $\begin{array}{l}\text { Hembras : IC }[24.06 \leq \pi \leq 45.18]=0.95 \\
\text { Machos : IC }[3.79 \leq \pi \leq 18.13]=0.95\end{array}$ \\
& & Hembras : IC $[9.92 \leq \pi \leq 26.66]=0.95$
\end{tabular}

Cuadro 4. Resultados de la evaluación serológica cuantitativa (\%) por Hemaglutinación Indirecta de cerdos que resultaron positivos a la prueba según tipo de crianza y sexo.

\begin{tabular}{ccccc}
\hline Dilución & \multicolumn{2}{c}{ Crianza tecnificada } & \multicolumn{2}{c}{ Crianza no tecnificada } \\
\cline { 2 - 5 } & $\begin{array}{c}\text { Machos } \\
(\mathrm{n}=12)\end{array}$ & $\begin{array}{c}\text { Hembras } \\
(\mathrm{n}=27)\end{array}$ & $\begin{array}{c}\text { Machos } \\
(\mathrm{n}=8)\end{array}$ & $\begin{array}{c}\text { Hembras } \\
(\mathrm{n}=15)\end{array}$ \\
\hline $1: 16$ & 25.0 & 33.3 & 12.5 & 20.0 \\
$1: 32$ & 58.4 & 40.8 & 37.5 & 26.7 \\
$1: 64$ & 8.3 & 11.1 & 37.5 & 46.6 \\
$1: 128$ & 8.3 & 11.1 & 12.5 & 6.7 \\
$1: 256$ & 0.0 & 3.7 & 0.0 & 0.0 \\
\hline Total & 100.0 & 100.0 & 100.0 & 100.0 \\
\hline
\end{tabular}


Esta significancia estadística ( $\mathrm{p}<$ $0,05)$ concuerda con el reportado por Vásquez (1988), quien usando la misma prueba halló frecuencias de $68 \%$ en crianza tecnificada y $54 \%$ en crianza no tecnificada.

Al considerar las frecuencias de los cerdos según el tipo de crianza, solamente dos investigadores hicieron este análisis y ambos reportaron valores superiores al hallado en el presente estudio en los animales de crianza tecnificada, así, Vásquez (1988) encontró $68 \%$ y D’Angelino e Ishizuka (1986) hallaron $46.6 \%$ de reactores. En relación a los animales procedentes de crianza no tecnificada, la frecuencia de positivos en el presente estudio es inferior a los encontrados por los mismos autores, que reportaron $54 \%$ y $42.7 \%$ respectivamente, a través de la misma técnica diagnóstica.

Al comparar las frecuencias de reactores, se puede observar que en caso de los cerdos de crianza tecnificada, la frecuencia de positivos es similar a los obtenidos por Nene, et al. (1986), Manuel, et al. (1974) y, Manuel y Tubongbanua (1977) que encontraron $26.62 \%, 28.4 \%$ y $25.38 \%$, respectivamente, mientras que en cerdos procedentes de crianza no tecnificada, concuerda con los hallazgos de McIlwain (1969), que encontró 14.4 $\%$ de positivos; además es similar al $19.4 \%$ y $19.2 \%$ citados por Arámbulo III, et al. (1974) y Hugh - Jones et al. (1986) respectivamente, quienes también emplearon la hemaglutinación indirecta como prueba diagnóstica; sin embargo, ellos no diferenciaron el tipo de crianza y, también es similar al reportado por Davies et al. (1988) quienes usando la prueba de aglutinación modificada hallaron $19.05 \%$ de reactores.
Por otro lado, considerando la hemaglutinación indirecta en el diagnóstico, nuestros hallazgos muestran valores inferiores a los reportados por Chhabra, et al. (1985), Ishii, et al. (1972), Mayer, et al. (1967) y Manuel, et al. (1974) que encontraron $31.5 \%$; 35\%; $35 \%$ y $38.59 \%$ respectivamente y otros investigadores que emplearon otras técnicas serológicas de diagnóstico; así, Suárez, et al. (1998) usando ELISA hallaron $33.33 \%$ de reactores; Dubey, et al. (1992) y Gamble, et al. (1992) encontraron $67.3 \%$ y $90.6 \%$ respectivamente, mediante la prueba de aglutinación.

Las diferencias de las frecuencias de reactores a toxoplasma con otros estudios pueden deberse a factores como: Tipo de explotación, considerando que la mayoría de estudios reportados se han realizado sin especificación del tipo de manejo; o al método de diagnóstico, debido a que las diversas técnicas muestran diferentes sensibilidades y especificidades.

Al analizar la distribución de animales reactores a toxoplasmosis según el sexo en animales procedentes de crianza tecnificada, se observa una mayor frecuencia en las hembras ( $\mathrm{p}<0.05$ ), hallazgo que concuerda con el reportado por Montoya, et al. (1981), quienes usando la misma técnica serológica en cerdos de raza York encontraron 31\% de positivos entre las hembras y $4 \%$ en machos; sin embargo, en el mismo trabajo, se observan mayor frecuencias de machos de otras razas, a pesar que cuando se consideran todas las razas en conjunto no se observó diferencia relacionada al sexo.

Igualmente nuestro hallazgo difiere de otros resultados que manifiestan falta de asociación entre animales reactores y el sexo, como el de Vásquez (1988), quien encontró $45 \%$ en machos y $55 \%$ en hembras $(\mathrm{p}>0.05)$; 
Silva, et al. (1981) que hallaron $2.6 \%$ en machos y $4.6 \%$ en hembras ( $\mathrm{p}>0.05$ ); igualmente Tamayo, et al. (1990) encontraron $26.1 \%$ en machos positivos y $29.9 \%$ en hembras positivas, mostrando ausencia de asociación estadística ( $p>0.05$ ); mientras que Torres, et al. (1991) mediante la prueba de carbono inmunoensayo determinaron $67 \%$ de positivos en hembras y $91 \%$ en machos mostrando asociación estadística $(\mathrm{p}<0.05)$ pero con mayor frecuencia en los machos.

En lo que se refiere a crianza no tecnificada, también se observa una mayor frecuencia en las hembras ( $\mathrm{p}>0.05$ ), hallazgo que concuerda con los reportados por Tamayo, et al. (1990) que hallaron $26.1 \%$ en machos y $29.9 \%$ en hembras ( $p>0.05$ ); por Vásquez (1988), quien encontró $45 \%$ en machos y $55 \%$ en hembras ( $\mathrm{p}>0.05$ ); igualmente por Silva; et al. (1981) quienes encontraron $2.6 \%$ en machos y $4.6 \%$ en hembras ( $\mathrm{p}>0.05$ ).

La diferencia en positividad según sexo encontrada en este estudio, no tiene una explicación lógica y al no conocerse trabajos en donde se estudien estas variables, se carecen de elementos de juicios suficientes como para formular alguna hipótesis al respecto.

En relación a la prueba de Hemaglutinación Indirecta es una prueba inmunológica práctica, de bajo costo y fácil de realizar. En las pruebas cualitativas se usó una dilución $1: 16$, debido a que una muestra positiva en esta dilución es indicativa de que el cerdo está o estuvo expuesto al parásito.

Con los resultados de las evaluaciones serológicas cuantitativas (Cuadros 2 y 4) se observa que la mayoría de los cerdos procedentes de ambos tipos de crianza son positivos a bajas diluciones (1:16, 1:32 y 1:64) indicando que el título de anticuerpos contra Toxoplasma gondii es bajo, pero los cerdos pueden manifestar la enfermedad en cualquier momento, en especial si no se controlan las posibles causas de transmisión de la enfermedad como por ejemplo la población de gatos observada en las instalaciones de la crianza tecnificada.

El hallazgo de frecuencias significativas $(25.16 \%$ y $14.84 \%)$ de cerdos reactores a toxoplasmosis procedentes de una crianza tecnificada y no tecnificada es sólo de valor interno, recomendándose la realización de otro estudio comparativo.

\section{Corrolusiones}

- Los cerdos provenientes de una granja de crianza tecnificada tuvieron una frecuencia de toxoplasmosis porcina mayor $(25.16 \%)$ que los cerdos provenientes de una crianza no tecnificada (14.84\%), encontrándose una asociación entre tipo de crianza y animales reactores a la toxoplasmosis $(\mathrm{P}<0.05)$.

- Se ha demostrado la presencia de Toxoplasma gondii en dos tipos de crianza porcina del valle de Lima, por lo que el cerdo sería una fuente importante de transmisión de la enfermedad para los humanos, en especial si consume la carne cruda o parcialmente cocida.

- La Hemaglutinación Indirecta es una prueba de mucha importancia para la detección rápida de cerdos con anticuerpos contra Toxoplasma gondii por su reducido costo, su simplificidad y su aplicación masiva. 


\section{Agrotermbert}

Al Laboratorio de Virología de la FMV-UNMSM y en especial a la Dra. Hermelinda Rivera por su invalorable colaboración en los análisis serológicos.

\section{Wherimin ortith}

1. Arambulo III, P.V.; B.D. Cabrera y M.H. Alge. 1974. Serological Survey of Toxoplasmosis in Pigs in the Philippines. Southeast Asian J. Trop. Med. Pub. Hlth. 5 (1): 9-11.

2. Asociación Peruana De Porcicultores. 1999. VII Seminario Internacional de Porcicultura. 21 de Mayo de 1999. Lima - Perú. 105 pp: 2,31 .

3. Chhabra, M.B.; S.L. Gupta y O.P. Gautam. 1985. Toxoplasma Seroprevalence in Animals in Northern India. Int. J.Zoon. 12 (2): 136 - 142.

4. Daniel, W.W. 1996. Bioestadística. Base para el análisis de las ciencias de la salud. $5^{\text {a }}$ ed. Uteha Noriega Ed., México. pp. 205-207.

5. D'Angelino, J.L. y M.M. Ishizuka. 1986. Toxoplasmose suína. 3. Avaliaçâo da Prevalência de Infecçâo toxoplásmica en Rebanhos suínos pela prova de Imunofluorescência indireta e Hemaglutinaçâo. Boletín de la Oficina Sanitaria Panamericana. 100(6):634645.

6. Davies, P.R.; W.E. Morrow; J.Deen, H.R. Gamble y S. Patton. 1998. Seroprevalence of Toxoplasma gondii and Trichinella spiralis in finishing swine raised in different production systems in North Carolina, USA. Prev Vet Med. Jul 17, $36(1): 67-76$.

7. Dubey, J.P.; H.R. Gamble; A.O. Rodriguez y P. Thulliez. 1992. Prevalence of antibodies to Toxoplasma gondii and Trichinella spiralis in 509 pigs from 31 farms in Oahu, Hawaii. Vet Parasitol, 43: 57-63.

8. Gamble, H.R.; R.C. Brady y J.P. Dubey. 1999. Prevalence of Toxoplasma gondii infection in domestic pigs in the New England states. Vet Parasitol. 82 (2): $129-136$.

9. García, Z.; R. Rosario; G. Díaz y o. Hernández. 1993. Seroprevalence of Toxoplasma gondii infection in cattle, swine and goats in four Mexican states. Preventive Veterinary Medicine. $17(1-2)$ : 127 - 132 .

10. Hove, T. y J.P. Dubey. 1999. Prevalence of Toxoplasma gondii antibodies in sera domestic pigs and some wildgame species from Zimbabwe. J Parasitol. 85 (2): 372-373.

11. Hugh-Jones, M.E.; J.J. Broussard; T.B. Stewart; C. Raby y J.E. Morrison. 1986. Prevalence of Toxoplasma gondii antibodies in southern Louisiana swine in 1980 and 1981. Am. J. Vet. Res. 47 (5): 1050 1051.

12. Ishii, A.; Y. Noboru y Y. Kawai. 1972. Indirect Hemagglutination Test for Toxoplasma Infection in Pigs and Men on Amami Oshima Island, Southern Japan. Japan. J. Exp. Med. 42 (1): 81 - 83.

13. Manuel, M.F.; C.B. Mendoza y J.A. Navarro. 1974. A Serological Survey of the Incidence of Toxoplasmosis in Swine. Philipp. J. Vet. Med. $13(1-2)$ : $187-199$.

14. Manuel, M.F. y R. Tubongbanua. 1977. A Serological Survey on the Incidence of Toxoplasmosis among Slaughtered Pigs in Metro Manila. Philipp. J. Vet. Med. $16(1-2): 9-19$. 15. Mayer, H.F. y I.K. De Boehringer. 1967. Nuevas Comprobaciones sobre Toxoplasmosis Animal en la Argentina. Revista de Medicina Veterinaria. 48 (4): $341-349$. 
16. Mcilwain, P. K. 1969. Prevalence of Antibodies to Toxoplasma gondii in Domestic Animals of North Dakota. Arch Environ Health. 19(6): 885-886.

17. Montoya, F.; L. Ramirez; A. Loaiza; J. Henao y G. Murillo. 1981. Prevalencia de Anticuerpos para Toxoplasma gondii en Bovinos y Porcinos. Boletín de la Oficina Sanitaria Panamericana. 91 (3): 219-226.

18. Nene, S.S.; B. N. Joshi y J. Patki. 1986. Toxoplasma Antibodies in Local Domestic Animals. Int. J. Zoon. 13(3): $187-189$.

19. Silva, N.; E. Chaplin; L. Mendez y F. Araujo. 1981. Determinaçao de Anticorpos toxoplásmicos em soros de suínos abatidos em matadouros, na regiao do Alto Taquarí, RS, Brasil. Arq. Fac. Vet. UFRGS Porto Alegre, 9: 3338.
20. Suárez, F.; H. Andrade; A. Jimenez; A. Hung, A. y C. Huallanca. 1998. Frecuencia de anticuerpos antiToxoplasma gondii en cerdos destinados al consumo humano mediante la prueba de ELISA. XII Reunión Científica APPA. pp: 241-243.

21. Tamayo, R.; M. Contreras; $M$. Méndez y M. Castro. 1990. Toxoplasmosis en cerdos beneficiados en las plantas faenadoras de Temuco y Valdivia, Chile. Arch. Med. Vet.; 22 (1): $95-99$.

22. Vásquez, R. 1988. Estudio Serológico sobre Toxoplasmosis en Ganado Porcino beneficiado en Lima - Perú 1 985. Tesis para optar el Título de Médico Veterinario. Facultad de Medicina Veterinaria. Universidad Nacional Mayor de San Marcos. Lima. Perú. 43 p. 